\title{
Progress in the Use of Adeno-Associated Viral Vectors for Gene Therapy
}

\author{
Hildegard Büning ${ }^{a}$ Markus Braun-Falco ${ }^{b}$ Michael Hallek ${ }^{a, c, d}$ \\ aLaboratorium für Molekulare Biologie, Genzentrum, Ludwig-Maximilians-Universität München, \\ bKlinik und Poliklinik für Dermatologie und Allergologie am Biederstein, Technische Universität München, and \\ cGSF, National Research Center for Environment and Health, München, and dKlinik I für Innere Medizin, \\ Universität zu Köln, Köln, Germany
}

\section{Key Words}

Adeno-associated virus · Epidermis · Genodermatosis • Wound healing

\begin{abstract}
The development of safe and efficient gene transfer vectors is crucial for the success of gene therapy trials. A viral vector system promising to meet these requirements is based on the apathogenic adeno-associated virus (AAV-2), a member of the parvovirus family. The advantages of this vector system is the stability of the viral capsid, the low immunogenicity, the ability to transduce both dividing and non-dividing cells, the potential to integrate site specifically and to achieve long-term
\end{abstract}

\section{Abbreviations used in this paper}

AAV-2 adeno-associated virus type 2

EGFR TK epidermal growth factor receptor tyrosine kinase

FALDH fatty aldehyde dehydrogenase

HSPG heparan sulfate proteoglycan

ITR inverted terminal repeats

ORF open reading frame gene expression even in vivo, and its broad tropism allowing the efficient transduction of diverse organs including the skin. All this makes AAV-2 attractive and efficient for in vitro gene transfer and local injection in vivo. This review covers the progress made in AAV vector technology including the development of AAV vectors based on other serotypes, summarizes the results obtained by AAV targeting vectors and outlines potential applications in the field of cutaneous gene therapy.

Copyright $\odot 2004$ S. Karger AG, Basel

\section{Introduction}

The skin is a very attractive organ for the development of new therapeutic approaches not only for its easy accessibility, but also for safety issues including the unique possibility to monitor the treatment site and, in case of side effects, to excise the affected site, as well as the large number of different diseases that are principally suitable for cutaneous gene transfer. Among these opportunities are genetic immunization, skin cancer, chronic wounds, primary monogenic skin diseases and systemic diseases characterized by low or absent amounts of circulating proteins [for review, see Braun-Falco and Hallek, 1998; Watt, 2000; Braun-Falco, 2002; Khavari et al., 2002]. Depend-

Prof. Dr. Michael Hallek

Klinik I für Innere Medizin, Universität zu Köln

Joseph-Stelzmann-Strasse 9

DE-50924 Köln (Germany)

Tel. +49 221478 4400, Fax +49 221478 5455, E-Mail Michael.Hallek@uni-koeln.de
Fax + 41613061234

E-Mail karger@karger.ch

www. karger.com

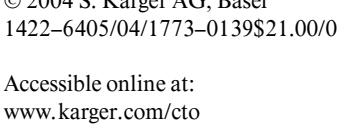


Fig. 1. Schematic description of the AAV-2 genome. The wild-type AAV-2 genome contains 4,680 nucleotides. The viral promoters (p5, p19 and p40), the ITR structures and the common polyadenylation signal are shown at the top. Rep78 and its splice variant Rep68 are controlled by the $\mathrm{p} 5$ promoter and are necessary for viral replication, transcription and site-specific integration. Rep52 and its splice variant Rep40 are transcribed from the p19 promoter. They are necessary for packaging the single-stranded genome. The viral capsid proteins (VP1, VP2 and VP3) are controlled from the p40 promoter. The three capsid proteins differ in their N-termini due to alternative splicing and different initiation codon usage, but share the VP3 region.

ing on the disease that should be treated by genetic modulation, the application of a gene transfer vehicle has to fulfill distinctive requirements regarding the efficiency of gene transfer, durability of gene expression, specificity of the target tissue and safety. The development of such an efficient and safe vector still remains one of the main hurdles to be overcome in the field of cutaneous as well as general gene therapy.

Although many improvements of non-viral vector systems have been achieved, viral vectors seem to be more efficient based on their long evolved strategies for cell entry. Moreover, for most of the viral systems targeting strategies have been successfully developed, which is a major step forward with respect to safety, efficiency and selectivity [Nicklin and Baker, 2002; Büning et al., 2003; Thomas et al., 2003]. One of these viral vectors is based on the adeno-associated virus type 2 (AAV-2). AAV-2 is currently being used in several human gene therapy trials, including hemophilia B and cystic fibrosis [Stilwell and Samulski, 2003]. Especially the long-term gene expression with mostly no sign of cytotoxic T-cell response to the AAV capsid or transgene product [Jooss and Chimule, 2003] makes AAV-2 a very promising vector system also for cutaneous gene therapy.

\section{From Virus to Vector}

AAV-2 was discovered as a co-infecting agent during an adenovirus outbreak. Until now no human disease caused by AAV-2 has been identified [Blacklow et al.,1968; Blacklow et al., 1971; Blacklow, 1988]. AAV-2 itself is a single-stranded, replication-deficient DNA virus consisting of an icosahedral protein capsid and a genome of 4,680 nucleotides comprising two open reading frames (ORF) [Carter and Samulski, 2000]. Although genotoxic

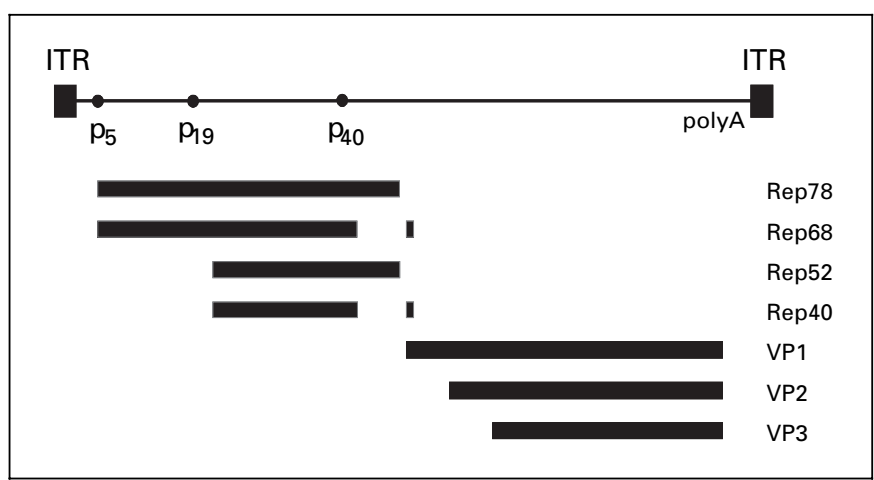

agents (e.g. UV irradiation, $\gamma$-irradiation, hydroxyurea, topoisomerase inhibitors, and various chemical carcinogens) can support a productive infection [Yalkinoglu et al., 1988; Yakobson et al., 1989; Yalkinoglu et al., 1991; Russell et al., 1995] efficient progeny production needs helper virus functions, normally provided by adenovirus or herpesvirus. Lacking a helper virus, the virion latently infects by integrating into the host genome. This integration occurs in $70 \%$ of the cases at a specific locus in the $q$ arm of human chromosome 19 within 19q13.4 termed AAVS1 [Kotin et al., 1990; Samulski et al., 1991; Kotin et al., 1992; Giraud et al., 1994; Dutheil et al., 2000]. For this unique feature AAV-2 needs the inverted terminal repeats (ITRs), which are flanking the viral genome on both sites, and the expression of the viral Rep proteins Rep78 and Rep68 (fig. 1). These multifunctional proteins are encoded, together with two additional family members (Rep52 and Rep40), in the 5' ORF of the viral genome. The 3' ORF accommodates (fig. 1) the three capsid proteins VP1 (90 kD), VP2 (72 kD) and VP3 (60 kD). They share overlapping sequences and differ only at their $\mathrm{N}$-termini, building the AAV-2 capsid with a relative stoichiometry of about 1:1:20 [Rabinowitz and Samulski, 2000].

Both ORFs are normally replaced by the transgene, since the only cis elements necessary for the generation of recombinant AAV-2 vectors ( $\mathrm{AAAV}-2$ ) are the viral ITR structures (fig. 2) [Carter and Samulski, 2000]. These 'gutless' vectors are no longer able to integrate site specifically, since the Rep proteins are missing. Although Nakai et al. [2003] observed that random integration into active genes in vivo occurs, these are very rare events. The majority of rAAV-2 genomes remain in an episomal state [Nakai et al., 2001; Schnepp et al., 2003]. However, there is the possibility to integrate ITR-flanked transgenes site specifically into the human chromosome 19 by providing 
Fig. 2. Schematic description of wild-type and recombinant AAV-2. For the production of rAAV-2 both open reading frames (Rep and Cap) of the wild-type AAV genome are replaced by the transgene. Therefore, the viral functions (integration, replication and new viral production) are lost in rAAV-2, which, as a 'gutless' vector, is shuttling the transgene into the cell.

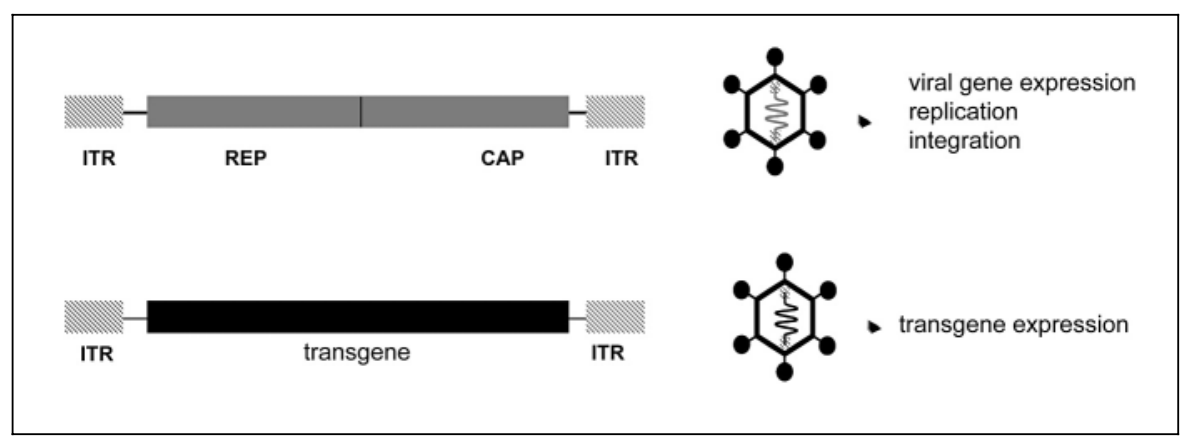

the Rep coding sequence in cis or in trans [Balague et al., 1997; Surosky et al., 1997; Huttner et al., 2003b].

Although packaging cell lines for the production of rAAV-2 have been described [Liu et al., 2000; Qiao et al., 2002a, 2002b], rAAV-2 are still mostly produced by transfection. Until the cloning of adenoviral helper plasmids (e.g. pXX6 or pDG) [Grimm et al., 1998; Xiao et al., 1998], which encodes adenoviral genes necessary for rAAV-2 production, rAAV-2 vectors were generated by transfection of a vector plasmid (encodes the transgene flanked by ITRs) and an AAV-2 helper plasmid (provides Rep and capsid proteins) into HeLa or 293 cells followed by infection with a helper virus (adenovirus or herpesvirus) [Ferrari et al., 1997; Girod et al., 1999]. Now, the helper virus can be substituted by the adenoviral helper plasmids thus avoiding helper virus contamination [Grimm et al., 1998; Xiao et al., 1998; Grimm et al., 1999]. Furthermore, improvements in the purification protocols using iodixanol gradients and/or heparin affinity chromatography resulted in $\mathrm{rAAV}-2$ preparation of high titer $\left(>10^{10}\right.$ transducing $\left.\mathrm{rAAV}-2 / \mathrm{ml}\right)$ and purity.

\section{AAV Serotypes}

AAV-2 was the first serotype from which recombinant vectors could be produced and from which the atomic structure has been determined by X-ray crystallography [Xie et al., 2002]. In the meantime, eight serotypes (AAV1 to AAV-8) have been identified. Sequence comparison among them revealed the greatest divergence in the capsid proteins [Rabinowitz and Samulski, 2000; Gao et al., 2003; Stilwell and Samulski, 2003] and here especially in the regions responsible for antibody and receptor binding. This leads to differences in both tropism [Halbert et al., 2001; Gao et al., 2002; Ding et al., 2003; Grimm et al., 2003] and serological neutralization [reviewed in Sun et

Adeno-Associated Viral Vectors for

Gene Therapy al., 2003]. Pseudotyping techniques were developed, which allow to package expression cassettes flanked by the AAV-2 ITRs into capsids of alternative serotypes [Gao et al., 2002; Rabinowitz et al., 2002; Grimm et al., 2003]. This allows to optimize gene delivery for selected applications and may circumvent problems with preexisting immunity.

Hauck et al. [2003] generated chimeric viruses and combined the abilities of different serotypes. They produced AAV-1/AAV-2 chimeras and could purify these viruses by heparin chromatography (ability obtained from AAV-2) and could efficiently transduce muscle (ability obtained from AAV-1) and liver cells (ability obtained from AAV-2) in vivo. However, until now only receptors for AAV-2, -4 and -5 are described. Heparan sulfate proteoglycan (HSPG), a widely distributed cell surface molecule, was identified as the primary receptor for AAV-2 and is bound by AAV-3 as well [Summerford and Samulski, 1998; Rabinowitz et al., 2002], whereas sialic acid seems to be the attachment receptor for AAV-4 ( $\alpha$ 2-3 O-linked) and AAV-5 ( $\alpha$ 2-3 N-linked) [Kaludov et al., 2001]. Mutational analysis and the determination of the three-dimensional structure made it possible for AAV-2 to assume how the capsid interacts with the glycan moiety of HSPG and to identify the arginine residues R585 and R588 in the AAV-2 capsid as the essential residues in this interaction [Xie et al., 2002; Opie et al., 2003]. For all the other serotypes this remains still unclear.

\section{AAV-2 Infectious Biology}

Many steps of the virus:cell interaction are still unknown. However, a model has been developed, based on results obtained with the cervix carcinoma cell line HeLa. Single virus tracing measurements showed that AAV-2

Cells Tissues Organs 2004;177:139-150 
moves in solution by free diffusion and that in the vicinity of the cell, the velocity of AAV-2 decelerates [Seisenberger et al., 2001]. After repetitive contacts with the cell membrane AAV-2 binds to the negatively charged HSPG on the cell surface [Summerford and Samulski, 1998; Seisenberger et al., 2001]. This attachment is enhanced by fibroblast growth factor receptor 1 binding [Qing et al., 1999]. After interaction with $\alpha_{v} \beta_{5}$ integrins [Summerford et al., 1999], AAV-2 enters the cell by a receptor-mediated endocytosis through clathrin-coated pits [Duan et al., 1999; Bartlett et al., 2000]. Activation of the small GTPbinding protein Rac1, which is assumed to be mediated by the integrin binding, leads to the stimulation of the phosphatidylinositol-3-kinase pathway [Sanlioglu et al., 2000]. This stimulation results in rearrangements of the cytoskeleton, which allows the trafficking of AAV-2-containing endosomes [Sanlioglu et al., 2000]. After acidification, AAV-2 is released from the endosomes at the late endosomal stage [Douar et al., 2001] and reaches the nucleus probably via the nuclear pore complexes. In the nucleus the viral genome is replicated or integrated into the host cell genome depending on the presence or absence of a helper virus. For the AAV-2-based vectors it is assumed that they infect the cell using the same steps; however neither replication nor site-specific integration can occur.

\section{Basic Aspects of rAAV-Mediated Transduction of Keratinocytes}

In the past, AAV-2 vectors have been tested for efficacy in a variety of different cell types with variable success [Maass et al., 1998]. For example, cells originating from muscle, brain, liver, and bronchial epithelia turned out to be highly permissive for AAV-2 infection [Xiao et al., 1996; Snyder et al., 1997; During et al., 1998; Guy et al., 1999; Herzog et al., 1999; Sanlioglu et al., 2001], whereas cells of the megakaryocytic origin or vascular endothelial cells showed only low transduction efficiencies [Ponnazhagan et al., 1996, 1997; Nicklin et al., 2001]. This explains why the first clinical trials using AAV-2 as a vector were approved for treatment of hemophilia by targeting the liver and muscles [Manno et al., 2003] (information by Avigen), for Parkinson disease by vector injection into the striatum [During et al., 2001] (information by Avigen) and for cystic fibrosis by transfection of bronchial epithelia [Flotte et al., 2003; Moss et al., 2004].

rAAV-mediated gene transfer into the skin has been demonstrated with considerable efficacy as well. For ex- ample, in an in vitro setting, rAAV-2 allowed transduction of up to $70 \%$ of primary human keratinocytes, the preponderant cell type of the epidermis (fig. 3) [BraunFalco et al., 1999], indicating that the cells are per se permissive for rAAV vector particles. In vivo gene transfer into porcine skin has been successfully demonstrated by Hengge and Mirmohammadsadegh [2000] after intradermal injection of rAAV particles, which let to a transgene expression in epidermal keratinocytes and adnexal structures for more than 6 weeks. In mice, subcutaneous injection of rAAV particles resulted in a durable transgene expression within the panniculous carnosus that lasted for several months [Donahue et al., 1999].

It is not surprising that human keratinocytes are permissive for rAAV-2, since they express HSPG on their surface as well as members of the fibroblast growth factor receptor family and integrins, all the rAAV receptors necessary for binding and uptake of vector particles through the cell membrane [Kim et al., 1994; Marchese et al., 1997; Lundqvist and Schmidtchen, 2001]. However, the susceptibility of keratinocytes for AAV-2 in relation to the highly permissive HeLa cells seems relatively low. An impaired intracellular trafficking of rAAV due to ubiquitination of viral particles has been shown in some cell types to limit high-efficient transduction [Duan et al., 2000b; Hansen et al., 2000]. This may also be true at least in part for keratinocytes [unpubl. data]. Nevertheless, this barrier can be overcome by decreasing ubiquitination using proteasome inhibitors. Since proteasome inhibitors are currently under investigation as anti-cancer agent in phase I and II human trials, so far with good safety profiles at active doses [Adams, 2002], they may be suitable for clinical application as rAAV-2 enhancers.

Another point to consider in the infectious process is the role of the epidermal growths factor receptor tyrosine kinase (EGFR TK). After entering the nucleus, conversion of the single-stranded viral DNA into a transcriptionally active double-stranded conformation is known to be the rate-limiting step before transgene expression can occur. The activity of this process has been found to correlate with the phosphorylation state of a cellular tyrosine phosphoprotein, designated single-stranded D-sequencebinding protein [Qing et al., 1998]. The phosphorylation of this protein itself is regulated by EGFR TK in a way that specific inhibition of EGFR TK finally results in an enhancement of transgene expression [Mah et al., 1998; Smith et al., 2003]. Since members of the EGF family represent major autoregulatory factors for keratinocytes driving cell proliferation, modulating terminal differentiation and controlling epidermal homeostasis [Pittelkow et 


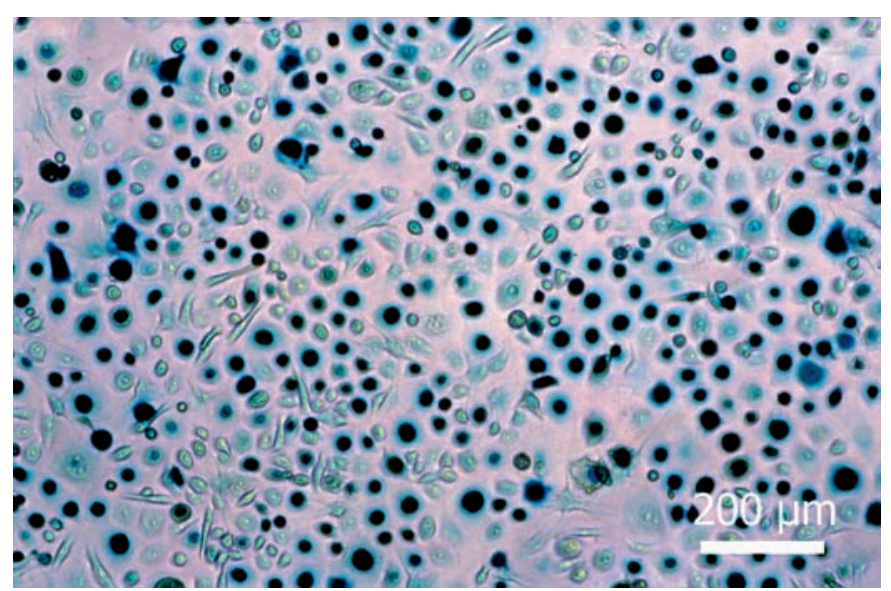

Fig. 3. High-efficient gene transfer of human keratinocytes with rAAV- 2 containing the gene for $\beta$-galactosidase (blue cells).

al., 1993; Peus et al., 1997], they may also influence the transduction of keratinocytes with rAAV vectors. Preliminary work points to this regulator role of EGFR TK [unpubl. data].

Such basic aspects help to optimize the transduction process of rAAV vectors into keratinocytes for the various indications of cutaneous gene therapy.

\section{Application of rAAV Vectors in Cutaneous Gene Therapy}

Among the different areas of cutaneous gene therapy, the acceleration of wound healing by gene transfer of growth factors has gained increasing interest in recent years [Braun-Falco, 2002]. Since the regulatory role of a number of cytokines has been elucidated within the different stages of normal wound healing [Goldman, 2004], great expectations have been laid in the topical application of recombinant growth factors. So far, only recombinant platelet-derived growth factor has been approved for the treatment of leg ulcers [Goldman, 2004]. The main drawback of the topical application of growth factors is their short half-life, fast degradation by proteases within the wound fluid and poor availability from ointments. These problems might be overcome by direct transfer of growth factor genes into the granulation tissue which may lead to a more sustained expression and profound effect of growth factors. AAV-2 vectors have already been applied for wound healing approaches with promising results. AAV-2-mediated gene transfer of vascular endo-
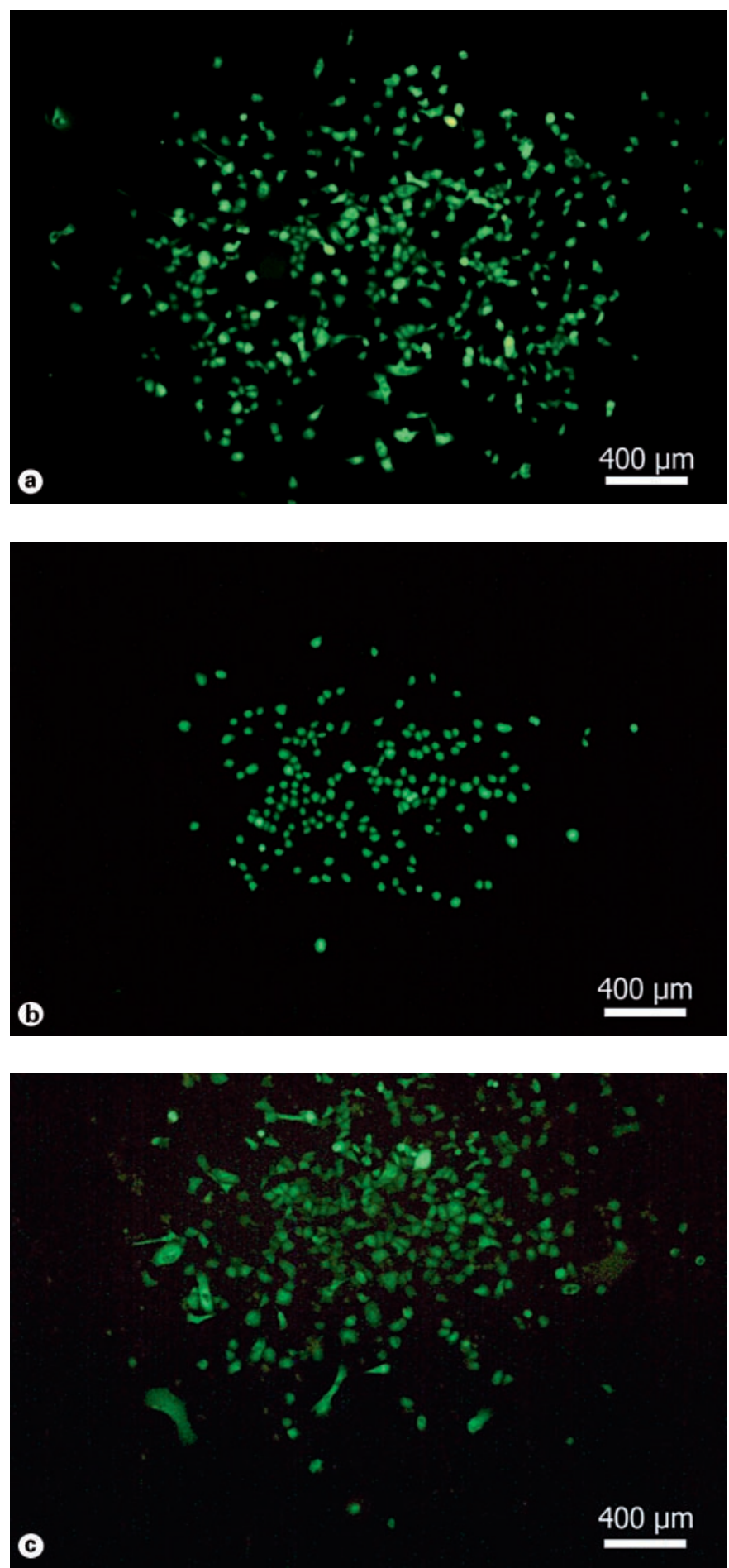

Fig. 4. Clonal growth of $\mathrm{AAAV}-2 /$ green fluorescent protein transduced keratinocytes. Keratinocytes were transduced with rAAV-2 containing the gene for green fluorescent protein and cultured at clonal density over several passages. Shown are passages $2-4$ at days 11 (a), 19 (b) and 27 (c) after transduction, each exhibiting clonal growth of green fluorescent keratinocytes. 
Table 1. Candidate genodermatoses for rAAV-mediated gene augmentation therapy

\begin{tabular}{|c|c|c|}
\hline Disease & Gene defect & $\begin{array}{l}\text { Functional cDNA } \\
\text { length }(\approx)\end{array}$ \\
\hline X-linked ichthyosis & steroid sulfatase & 1,550 \\
\hline Lamellar ichthyosis & transglutaminase 1 & 2,450 \\
\hline Sjögren-Larsson syndrome & fatty aldehyde dehydrogenase & 1,550 \\
\hline Junctional epidermolysis bullosa & laminin $5 \gamma 2$ chain (LAMC2) & 1,900 (truncated) \\
\hline Ehlers-Danlos type VI & lysyl hydroxylase 1 & 2,100 \\
\hline Refsum syndrome & phytanoyl-coenzyme A hydroxylase & 1,050 \\
\hline Gaucher syndrome & glucocerebrosidase & 1,650 \\
\hline \multicolumn{3}{|l|}{ Papillon-Lefevre/Haim-Munk } \\
\hline syndrome & cathepsin C & 1,900 \\
\hline Albinism type I & tyrosinase & 1,600 \\
\hline \multicolumn{3}{|l|}{ Congenital erythropoietic } \\
\hline porphyria & uroporphyrinogen III synthase & 1,300 \\
\hline Xeroderma pigmentosum & $\mathrm{XP}-\mathrm{A},-\mathrm{B},-\mathrm{C},-\mathrm{D}$ & $\begin{array}{l}910,2,400,2,500, \\
2,400\end{array}$ \\
\hline
\end{tabular}

thelial growth factor has shown to stimulate angiogenesis and wound healing in incisional skin wounds in diabetic mice, in experimental burn wounds in mice and in excisional wounds in rats [Deodato et al., 2002; Galeano et al., 2003a, 2003b].

Another application might be inherited diseases. Since AAV-2 vectors have shown to mediate long-term gene expression in animal models for more than 1 year in several organs (e.g. in muscles and neuronal tissue), they might be particularly useful for treatment approaches of genodermatoses, in which durable correction of the underlying genetic abnormality is necessary to achieve clinical benefit. In recent years, significant progress has been made in the molecular characterization of an increasing number of genodermatoses [Irvine and McLean, 2003]. Many of them have their underlying defect within the epidermis. The epidermis is known to be a lifelong selfrenewing tissue comprising stem cells within their basal layer, which upon division generates a new stem cell and a daughter cell that undergoes terminal differentiation [for review, see Watt, 2000]. In order to achieve durable gene expression the necessity to target keratinocyte stem cells is quiet obvious, otherwise gene expression will be lost after one epidermal turnover in approximately 4 weeks, independent on efficacy or integration. There are several ways to identify cells, which might have the potential to be a stem cell; even not a single is definitely specific. One in vitro possibility is to look for clonal growth properties [Barrandon and Green, 1987; Jones and Watt, 1993]. Figure 4 shows one of our own experiments, in which human keratinocytes have been transduced with $\mathrm{rAAV}-2$ vector particles carrying green fluorescent protein as transgene, thus allowing to follow growth properties of transduced cells cultured in the absence of a feeder layer. Without any selective pressure, transduced keratinocytes were able to form clones even after several passages and several weeks of culture indicating that keratinocytes with stem cell growth characteristics have been originally transduced.

Even rAAV-2 vectors may be able to transduce keratinocyte stem cells, one drawback may be a rapid vector dilution in rapidly dividing tissues in the absence of vector integration. Long-term transgene expression in muscle, for example, has not been attributed to integration, but primarily to the extremely low dividing rate of these particular tissue prolonging the dilution effect of nonintegrated episomal forms of the vector genome [Duan et al., 1998]. Although keratinocyte stem cells are known in vivo, in contrary to cultivation ex vivo, for having a very slow cell cycle, they still may have a higher proliferation rate than muscle tissue. Nevertheless, in airway epithelial cells, which have with 3-5 days a higher turnover rate than the epidermis, rAAV-mediated transgene expression persisted in vivo for more than 150 days [Duan et al., 2000b], allowing the speculation that gene expression from transduced epithelial stem cells may be more stable than from non-stem cells.

Which genodermatoses could theoretically be targeted with AAV-2 vectors? In principle the same genodermatoses as the ones considered candidate diseases for retroor lentiviral gene transfer, as long as the expression cassette containing the therapeutic gene does fit into the AAV-2 capsid with a packaging capacity of approximately $4.5 \mathrm{~kb}$. At first, a packaging capacity of $4.5 \mathrm{~kb}$ may appear as a considerable limitation, but even in a construct con- 
taining an endogenous promoter, e.g. a cytokeratin 14 promoter with a length of around $2 \mathrm{~kb}$, therapeutic sequences up to $2.5 \mathrm{~kb}$ can be inserted and packaged. Table 1 gives a selection of recessive genodermatoses with cDNA size below $2.5 \mathrm{~kb}$. Besides that, new developments have allowed to overcome the vector size limitation through viral DNA heterodimerization [Duan et al., 2000a; Sun et al., 2000]. This strategy relies on a unique feature of the rAAV-2 biology to form intermediate circular concatamers of two independent vector templates. Thus, a large gene and its endogenous promoter can be split into two individual rAAV vectors. After co-transfection of the target cell, the two vectors form head-to-tail heterodimers through identical sequence homology of the ITRs resulting in a rejoining of the split parts.

Our own work has focused on the Sjögren-Larsson syndrome, a neurocutaneous disease clinically characterized by generalized ichthyosis, mental retardation and spastic diplegia or tetraplegia. It is caused by an autosomal recessive defect in the gene coding for fatty aldehyde dehydrogenase (FALDH), an enzyme necessary for the oxidation of long-chain aliphatic aldehydes to fatty acids [Rizzo et al., 2001]. Using an AAV-2 vector containing the functional cDNA for FALDH, the FALDH activity in an FALDH-negative cell line may be increased to a level of heterozygous carriers which are phenotypically not altered [unpubl. data].

Besides gene augmentation and restoration approaches for recessive disorders, $\mathrm{rAAV}-2$ may be applicable to dominant diseases as well. There are different in situ repair and silencing strategies under development, e.g. the use of small DNA/RNA chimeric molecules, ribozymes, antisense nucleic acids or inhibitory RNA oligonucleotides [Khavari et al., 2002]. Theoretically, AAV-2 vectors may be suitable to deliver each of these genetic molecules. The successful rescue of a dominant rhodopsin mutation in rat photoreceptor cells through rAAV-2-mediated ribozymes has already been demonstrated [LaVail et al., 2000]. Moreover, AAV-2 seems capable to introduce specific genetic modifications at homologous chromosomal sequences in a gene targeting process, thus being able to correct substitutions, insertion and deletion mutations [Hirata and Russell, 2000].

Another potential application of cutaneous gene therapy uses the skin as a 'bioreactor'. Ideally, a circumscribed area of the body surface should be directly transduced or transplanted with genetically modified keratinocytes, leading to the production of a certain therapeutic gene product that passes the dermal-epidermal junction, reaches the bloodstream and is distributed in the circula- tion. This 'bioreactor' approach could be applicable to diseases with reduced or absent systemic proteins, e.g. hemophilia or anemia. For example, the subcutaneous injections of AAV-2 vectors encoding factor IX revealed long-term protein expression in the serum of mice for at least 1 year [Donahue et al., 1999]. In a nude mice model, AAV-2-transduced epidermal cells secreted erythropoietin, which was delivered systemically and resulted in an increased hematocrit [Descamps et al., 1996]. The great advantage of this approach in comparison to liverdirected gene delivery or intravenous injection of vector particles, for example, is that the modified skin can easily be monitored and excised in case of unexpected adverse effects.

\section{Targeting of AAV-2 Vectors}

Targeting of vectors to a particular tissue or cell type is an important issue to enhance the specificity of any therapeutic effect. For instance, in metastatic malignant melanoma, direct injection of cytokine-containing vectors into subcutaneous metastases might reduce tumor size locally, but usually lacking any systemic effect [Penel and Bonneterre, 2003]. Therefore, the target delivery of immunomodulatory genes specifically to tumor cells, unsystematically distributed within the whole body, will greatly improve an anti-tumor response. For the treatment of genodermatoses the importance of keratinocyte stem cell transduction has already be mentioned. Targeting approaches may facilitate this necessity. Targeting of AAV vectors can be performed at least at two levels, namely at the virus entry into the cells and at the transcriptional level. Here, we will focus on the receptor targeting approach, in which selective binding and entry only into the desired cell type is the rewarding task. Until now two different strategies direct and indirect targeting [Cosset and Russell, 1996] have been used to reach this goal.

The indirect targeting to a cell-specific receptor is mediated by an associated molecule, which is bound to the viral surface and interacts with a specific cell surface molecule [Miller, 1996]. Bartlett et al. [1999] used a bispecific antibody, which recognized simultaneously $\alpha_{\mathrm{IIb}} \beta_{3}$ integrin and the intact AAV-2 capsid. They employed this approach successfully for the transduction of MO7e and DAMI cells, which are not permissive for wild-type AAV-2 infection. Recently, Ponnazhagan et al. [2002] described another elegant approach for indirect targeting by using avidin-linked ligands conjugated to biotinylated rAAV-2 for the transduction of the human ovarian cancer 
cell line SKOV3.ip1 and like Bartlett et al. [1999] for the transduction of the AAV-2-refractory megakaryocytic cell line MO7e via EGFR and fibroblast growth factor receptor $1 \alpha$, respectively.

In the direct targeting strategy, a ligand- or receptorspecific single chain antibody is directly inserted into the viral capsid [Walter and Stein, 1996]. For AAV-2 it was shown that the inserted sequence is functional, when it is either fused to the N-terminus of VP2 [Yang et al., 1998; Wu et al., 2000] or inserted between amino acids 587 and 588 or after 588 in the VP3 region of the capsid [Girod et al., 1999; Grifman et al., 2001; Nicklin et al., 2001; Shi et al, 2001; Shi and Bartlett, 2003]. Other sites in the capsid have also been described, e.g. 161 (in the VP2 region), 459 and 584 (in the VP3 region), who are able to display an inserted sequence, but the functionality remains to be proven [Shi et al., 2001]. However, until now the most promising site for the insertion of a functional ligand is $587 / 588$. Since the VP3 region is also found in the VP2 and VP1 capsid proteins (fig. 1), a sequence inserted at this site is displayed 60 times on the AAV-2 capsid. The three-dimensional structure reveals that 587 is exposed at the viral surface, lying at the side of the peak, which forms the threefold symmetry axis. This site was first described by Girod et al. [1999], who inserted the L14 peptide which contains the RGD motif of the laminin fragment P1 [Aumailley et al., 1990] C-terminal of 587, and used the generated targeting vector to efficiently transduce B16F10 (mouse melanoma) and RN22 (rat Schwannoma) cell lines, which were not infected by wild-type AAV-2. The same site was also successfully used for the insertion of an endothelial-specific peptide isolated by phage display. By this, an AAV-2 targeting vector which is able to efficiently infect endothelial cells, e.g. human umbilical vein endothelial cells and human saphenous vein endothelial cells, was developed [Nicklin et al., 2001]. Using a CD13-specific peptide, which binds to the NGR receptor expressed on angiogenic vasculature and on many tumor cell lines, with the sequence NGRAHA for insertion between 587 and 588, Grifman et al. [2001] were able to target AAV-2 to KS1767 (Kaposi sarcoma) and RD (rhabdomyosarcoma) cells. Ried et al. [2002] used this site to generate a universal targeting vector by using a truncated version (Z34C) of the immunoglobulin-binding domain from protein A of Staphylococcus aureus [Ohno et al., 1997] as a coupling module. This coupling module can be used to bind cell-selective/-specific antibodies [Ried et al., 2002]. That this region works also in vivo could be shown by Shi and Bartlett [2003]. By insertion of a RGD-4C motif C-terminal of 588, which mediates the binding to $\alpha_{v}$ integrins, they generated an AAV-2 targeting vector which showed a clear enhancement in the transduction of SKOV-3 cells injected intraperitoneally into immunodeficient mice in comparison to unmodified AAV-2 vectors. Furthermore, White et al. [2004] showed that the AAV tropism can be genetically engineered by the use of phage display-derived peptides to generate vectors that are selective for the vasculature in vivo.

Since one characteristic of keratinocyte stem cells is a high $\beta_{1}$-integrin (CD29) expression [Jones and Watt, 1993], the use of this targeting vector together with antihuman CD29 antibodies may be a favorable strategy for targeting keratinocyte stem cells. For targeting malignant melanoma cells the EGFR may be a candidate even though expression is not solely restricted to melanoma cells.

Recently, Perabo et al. [2003] developed another promising technique, the adeno-associated virus display, to generate receptor-specific AAV-2 targeting vectors by a combinatorial approach. This new technology uses a library of AAV-2 capsid mutants carrying a randomized 7-mer peptide between 587 and 588 to select for receptorspecific AAV-2 capsid mutants. This library was used to infect the target cell line and was screened for capsid mutants who are able to infect and replicate in the target cells. After five selection rounds on the AAV-2 non-permissive cell line MO7e, Perabo et al. [2003] isolated an AAV-2 capsid mutant bearing the sequence RGDAVGV between 587 and 588. They could show that this sequence, when inserted between 587 and 588 of rAAV-2, confers the targeting vector with the ability to infect the target cell line MO7e efficiently in a receptor-specific manner. Applying the same approach on a B-cell chronic lymphocytic leukemia cell line (Mec1) resulted in a targeting vector able to efficiently infect cells of patients with B-cell chronic lymphocytic leukemia, which are refractory to AAV-2 infection. These new techniques will have enormous implications for the development of targeting AAV-2 vectors, as peptides are preselected within the architectural environment of AAV capsids for their targeting capacity without the need to know the respective cell surface molecule which mediates the binding and uptake into the targeting cell. This is important especially in the field of cutaneous gene therapy, where only a few cell surface molecules are known to be able to serve as targets of receptor-specific vectors. 


\section{Future Prospects}

With the discovery and utilization of the different serotypes, the improvements in vector production, the development of the AAV targeting technology and the determination of the three-dimensional structure of the AAV capsid, AAV-based vectors have developed to the vector system of choice for many applications including those of cutaneous gene therapy. However, there are still some limitations to be overcome. The quality of gene transfer concerning efficacy, duration of transgene expression and specific cell targeting still needs improvements for keratinocytes as well as malignant melanoma cells. Even though targeting vectors might be able to infect these cells in a receptor-specific manner, in most cases this transduction ability is not limited to one cell type. In addition, preexisting and newly generated neutralizing antibodies to the AAV-2 capsid are a hurdle at least for repeated vector applications. This can may be avoided by the use of differ- ent serotypes, which do not cross react, or the use of targeting vectors [Huttner et al., 2003a]. Forcing integration at a specific chromosomal location opposing the observation of random integration in actively transcribed genes is a point which needs to be further analyzed. However, the methods for further improvements are there and will result in second- and third-generation rAAV vectors usable for efficient, safe and selective gene therapy applications.

\section{Acknowledgments}

This work was supported by the 'Deutsche Forschungsgemeinschaft' (SFB 455, BR2004/1-1), the 'Bayerische Forschungsstiftung' and the 'Sander Stiftung'. We thank all members of the laboratory for many inspiring discussions and help during the work presented in this review. The authors apologize to investigators whose work was not cited due to limiting space.

\section{References}

Adams, J. (2002) Development of the proteasome inhibitor PS-341. Oncologist 7: 9-16.

Aumailley, M., M. Gerl, A. Sonnenberg, R. Deutzmann, R. Timpl (1990) Identification of the Arg-Gly-Asp sequence in laminin A chain as a latent cell-binding site being exposed in fragment P1. FEBS Lett 262: 82-86.

Balague, C., M. Kalla, W.W. Zhang (1997) Adenoassociated virus Rep78 protein and terminal repeats enhance integration of DNA sequences into the cellular genome. J Virol 71: 32993306.

Barrandon, Y., H. Green (1987) Three clonal types of keratinocyte with different capacities for multiplication. Proc Natl Acad Sci USA 84 2302-2306.

Bartlett, J.S., J. Kleinschmidt, R.C. Boucher, R.J. Samulski (1999) Targeted adeno-associated virus vector transduction of nonpermissive cells mediated by a bispecific $\mathrm{F}\left(\mathrm{ab}^{\prime} \gamma\right) 2$ antibody. Nat Biotechnol 17: 181-186.

Bartlett, J.S., R. Wilcher, R.J. Samulski (2000) Infectious entry pathway of adeno-associated virus and adeno-associated virus vectors. J Virol 74: 2777-2785.

Blacklow, N.R. (1988) Adeno-associated virus of humans; in Pattison, J.R. (ed): Parvoviruses and Human Disease. Boca Raton, CRC Press, pp 165-174.

Blacklow, N.R., M.D. Hoggan, A.Z. Kapikian, J.B. Austin, W.P. Rowe (1968) Epidemiology of adenovirus-associated virus infection in a nursery population. Am J Epidemiol 88: 368-378.
Blacklow, N.R., M.D. Hoggan, M.S. Sereno, C.D. Brandt, H.W. Kim, R.H. Parrot, R.M. Chanock (1971) A seroepidemiologic study of adenovirus-associated virus infection in infants and children. Am J Epidemiol 94: 359-366.

Braun-Falco, M. (2002) Gene therapy concepts for promoting wound healing (in German). Hautarzt 53: 238-243

Braun-Falco, M., A. Doenecke, H. Smola, M. Hallek (1999) Efficient gene transfer into human keratinocytes with recombinant adeno-associated virus vectors. Gene Ther $6: 432-441$.

Braun-Falco, M., M. Hallek (1998) Cutaneous gene therapy - Perspectives of gene transfer in keratinocytes (in German). Hautarzt 49: 536-544.

Büning, H., M.U. Ried, L. Perabo, F.M. Gerner, N.A. Huttner, J. Enssle, M. Hallek (2003) Receptor targeting of adeno-associated virus vectors. Gene Ther 10: 1142-1151.

Carter, P.J., R.J. Samulski (2000) Adeno-associated viral vectors as gene delivery vehicles. Int $\mathbf{J}$ Mol Med 6: 17-27.

Cosset, F.L., S.J. Russell (1996) Targeting retrovirus entry. Gene Ther 3: 946-956.

Deodato, B., N. Arsic, L. Zentilin, M. Galeano, D. Santoro, V. Torre, D. Altavilla, D. Valdembri, F. Bussolino, F. Squadrito, M. Giacca (2002) Recombinant AAV vector encoding human VEGF165 enhances wound healing. Gene Ther 9: 777-785.

Descamps, V., N. Blumenfeld, Y. Beuzard, M. Perricaudet (1996) Keratinocytes as a target for gene therapy. Sustained production of erythropoietin in mice by human keratinocytes transduced with an adenoassociated virus vector. Arch Dermatol 132: 1207-1211.
Ding, W., Z. Yan, R. Zak, M. Saavedra, D.M. Rodman, J.F. Engelhardt (2003) Second-strand genome conversion of adeno-associated virus type 2 (AAV-2) and AAV-5 is not rate limiting following apical infection of polarized human airway epithelia. J Virol 77: 7361-7366.

Donahue, B.A., J.G. McArthur, S.K. Spratt, D. Bohl, C. Lagarde, L. Sanchez, B.A. Kaspar, B.A. Sloan, Y.L. Lee, O. Danos, R.O. Snyder (1999) Selective uptake and sustained expression of AAV vectors following subcutaneous delivery. J Gene Med 1: 31-42.

Douar, A.M., K. Poulard, D. Stockholm, O. Danos (2001) Intracellular trafficking of adeno-associated virus vectors: routing to the late endosomal compartment and proteasome degradation. J Virol 75: 1824-1833.

Duan, D., Q. Li, A.W. Kao, Y. Yue, J.E. Pessin, J.F. Engelhardt (1999) Dynamin is required for recombinant adeno-associated virus type 2 infection. J Virol 73: 10371-10376.

Duan, D., P. Sharma, J. Yang, Y. Yue, L. Dudus, Y. Zhang, K.J. Fisher, J.F. Engelhardt (1998) Circular intermediates of recombinant adenoassociated virus have defined structural characteristics responsible for long-term episomal persistence in muscle tissue. J Virol 72: 85688577.

Duan, D., Y. Yue, Z. Yan, J.F. Engelhardt (2000a) A new dual-vector approach to enhance recombinant adeno-associated virus-mediated gene expression through intermolecular cis activation. Nat Med 6: 595-598. 
Duan, D., Y. Yue, Z. Yan, J. Yang, J.F. Engelhardt (2000b) Endosomal processing limits gene transfer to polarized airway epithelia by adenoassociated virus. J Clin Invest 105: $1573-$ 1587.

During, M.J., M.G. Kaplitt, M.B. Stern, D. Eidelberg (2001) Subthalamic GAD gene transfer in Parkinson disease patients who are candidates for deep brain stimulation. Hum Gene Ther 12: 1589-1591.

During, M.J., R.J. Samulski, J.D. Elsworth, M.G Kaplitt, P. Leone, X. Xiao, J. Li, A. Freese, J.R. Taylor, R.H. Roth, J.R. Sladek Jr., K.L. O'Malley, D.E. Redmond Jr. (1998) In vivo expression of therapeutic human genes for dopamine production in the caudates of MPTP-treated monkeys using an AAV vector. Gene Ther 5 . 820-827.

Dutheil, N., F. Shi, T. Dupressoir, R.M. Linden (2000) Adeno-associated virus site-specifically integrates into a muscle-specific DNA region. Proc Natl Acad Sci USA 97: 4862-4866.

Ferrari, F.K., X. Xiao, D. McCarty, R.J. Samulski (1997) New developments in the generation of Ad-free, high-titer rAAV gene therapy vectors. Nat Med 3: 1295-1297.

Flotte, T.R., P.L. Zeitlin, T.C. Reynolds, A.E. Heald, P. Pedersen, S. Beck, C.K. Conrad, L. Brass-Ernst, M. Humphries, K. Sullivan, R Wetzel, G. Taylor, B.J. Carter, W.B. Guggino (2003) Phase I trial of intranasal and endobronchial administration of a recombinant adenoassociated virus serotype 2 (rAAV2)-CFTR vector in adult cystic fibrosis patients: a twopart clinical study. Hum Gene Ther 14: 1079_ 1088

Galeano, M., B. Deodato, D. Altavilla, D. Cucinotta, N. Arsic, H. Marini, V. Torre, M. Giacca, F. Squadrito (2003a) Adeno-associated viral vector-mediated human vascular endothelial growth factor gene transfer stimulates angiogenesis and wound healing in the genetically diabetic mouse. Diabetologia 46: 546-555.

Galeano, M., B. Deodato, D. Altavilla, G. Squadrito, P. Seminara, H. Marini, F. Stagno d'Alcontres, M. Colonna, M. Calo, P. Lo Cascio, V. Torre, M. Giacca, F.S. Venuti, F. Squadrito (2003b) Effect of recombinant adeno-associated virus vector-mediated vascular endothelial growth factor gene transfer on wound healing after burn injury. Crit Care Med 31: 10171025 .

Gao, G., M.R. Alvira, S. Somanathan, Y. Lu, L.H Vandenberghe, R. Calcedo, J. Sanmiguel, Z. Abbas, J.M. Wilson (2003) Adeno-associated viruses undergo substantial evolution in primates during natural infections. Proc Natl Acad Sci USA 100: 6081-6086.

Gao, G.P., M.R. Alvira, L. Wang, R. Calcedo, J. Johnston, J.M. Wilson (2002) Novel adenoassociated viruses from rhesus monkeys as vectors for human gene therapy. Proc Natl Acad Sci USA 99: 11854-11859.

Giraud, C., E. Winocour, K.I. Berns (1994) Sitespecific integration by adeno-associated virus is directed by a cellular DNA sequence. Proc Natl Acad Sci USA 91: 10039-10043.
Girod, A., M. Ried, C. Wobus, H. Lahm, K. Leike, J. Kleinschimdt, G. Deleage, M. Hallek (1999) Genetic capsid modifications allow efficient retargeting of adeno-associated virus type 2 . Nat Med 5: 1052-1056.

Goldman, R. (2004) Growth factors and chronic wound healing: past, present, and future. Adv Skin Wound Care 17: 24-35.

Grifman, M, Trepel M, Speece P, L.B. Gilbert, W. Arap, R. Pasqualini, M.D. Weitzman (2001) Incorporation of tumor-targeting peptides into recombinant adeno-associated virus capsids. Mol Ther 3: 964-975.

Grimm, D., M.A. Kay, J.A. Kleinschmidt (2003) Helper virus-free, optically controllable, and two-plasmid-based production of adeno-associated virus vectors of serotypes 1 to 6 . Mol Ther 7: 839-850.

Grimm, D., A. Kern, K. Rittner, J.A. Kleinschmidt (1998) Novel tools for production and purification of recombinant adeno-associated virus vectors. Hum Gene Ther 9: 2745-2760.

Grimm, D., J.A. Kleinschmidt (1999) Progress in adeno-associated virus type 2 vector production: promises and prospects for clinical use. Hum Gene Ther 10: 2445-2450.

Guy, J., X. Qi, N. Muzyczka, W.W. Hauswirth (1999) Reporter expression persists 1 year after adeno-associated virus-mediated gene transfer to the optic nerve. Arch Ophthalmol 117: 929937.

Halbert, C.L., J.M. Allen, A.D. Miller (2001) Adeno-associated virus type 6 (AAV6) vectors mediate efficient transduction of airway epithelial cells in mouse lungs compared to that of AAV2 vectors. J Virol 75: 6615-6624.

Hansen, J., K. Qing, H.-J. Kwon, C. Mah, A. Srivastava (2000) Impaired intracellular trafficking of adeno-associated virus type 2 vectors limits efficient transduction of murine fibroblasts. J Virol 74: 992-996.

Hauck, B., L. Chen, W. Xiao (2003) Generation and characterization of chimeric recombinant AAV vectors. Mol Ther 7: 419-425.

Hengge, U.R., A. Mirmohammadsadegh (2000) Adeno-associated virus expresses transgenes in hair follicles and epidermis. Mol Ther 2: 188194.

Herzog, R.W., E.Y. Yang, L.B. Couto, J.N. Hagstrom, D. Elwell, P.A. Fields, M. Burton, D.A. Bellinger, M.S. Read, K.M. Brinkhous, G.M. Podsakoff, T.C. Nichols, G.J. Kurtzman, K.A. High (1999) Long-term correction of canine hemophilia B by gene transfer of blood coagulation factor IX mediated by adeno-associated viral vector. Nat Med 5: 56-63.

Hirata, R.K., D.W. Russell (2000) Design and packaging of adeno-associated virus gene targeting vectors. J Virol 74: 4612-4620.

Huttner, N.A., A. Girod, L. Perabo, D. Edbauer, J.A. Kleinschmidt, H. Buning, M. Hallek (2003a) Genetic modification of the adenoassociated virus type 2 capsid reduce the affinity and the neutralizing effects of human serum antibodies. Gene Ther 10: 2139-2147.
Huttner, N.A., A. Girod, S. Schnittger, C. Schoch, M. Hallek, H. Büning (2003b) Analysis of sitespecific transgene integration following cotransduction with recombinant adeno-associated virus (rAAV) and a rep encoding plasmid. J Gene Med 5: 120-129.

Irvine, A.D., W.H. McLean (2003) The molecular genetics of the genodermatoses: progress to date and future directions. Br J Dermatol 148: $1-13$.

Jones, P.H., F.M. Watt (1993) Separation of human epidermal stem cells from transit amplifying cells on the basis of differences in integrin function and expression. Cell 73: 713-724.

Jooss, K., N. Chirmule (2003) Immunity to adenovirus and adeno-associated viral vectors: implication for gene therapy. Gene Ther 10: 955963.

Kaludov, N., K.E. Brown, R.W. Walters, J. Zabner, J.A. Chiorini (2001) Adeno-associated virus serotype 4 (AAV4) and AAV5 both require sialic acid binding for hemagglutination and efficient transduction but differ in sialic acid linkage specificity. J Virol 75: 6884-6893.

Khavari, P.A., O. Rollman, A. Vahlquist (2002) Cutaneous gene transfer for skin and systemic diseases. J Intern Med 252: 1-10.

Kim, J.P., K. Zhang, J.D. Chen, R.H. Kramer, D.T. Woodley (1994) Vitronectin-driven human keratinocyte locomotion is mediated by the alpha $\mathrm{v}$ beta 5 integrin receptor. J Biol Chem 269: 26926-26932.

Kotin, R.M., R.M. Linden, K.I. Berns (1992) Characterization of a preferred site on human chromosome $19 \mathrm{q}$ for integration of adeno-associated virus DNA by non-homologous recombination. EMBO J 11: 5071-5078.

Kotin, R.M., M. Siniscalco, R.J. Samulski, X.D Zhu, L. Hunter, C.A. Laughlin, S. McLaughlin, N. Muzyczka, M. Rocchi, K.I. Berns (1990) Site-specific integration by adeno-associated virus. Proc Natl Acad Sci USA 87: 2211 2215.

LaVail, M.M., D. Yasumura, M.T. Matthes, K.A. Drenser, J.G. Flannery, A.S. Lewin, W.W. Hauswirth (2000) Ribozyme rescue of photoreceptor cells in $\mathrm{P} 23 \mathrm{H}$ transgenic rats: long-term survival and late-stage therapy. Proc Natl Acad Sci USA 97: 11488-11493.

Liu, X., F. Voulgaropoulou, R. Chen, P.R. Johnson, K.R. Clark (2000) Selective Rep-Cap gene amplification as a mechanism for high-titer recombinant AAV production from stable cell lines. Mol Ther 2: 394-403.

Lundqvist, K., A. Schmidtchen (2001) Immunohistochemical studies on proteoglycan expression in normal skin and chronic ulcers. Br J Dermatol 144: 254-259.

Maass, G., C. Bogedain, U. Scheer, D. Michl, M. Hörer, M. Braun-Falco, M. Volkenandt, D. Schadendorf, C. Wendtner, E.-L. Winnacker, R. Kotin, M. Hallek (1998) Recombinant adeno-associated virus for the generation of autologous, gene-modified tumor vaccines: evidence for a high transduction into primary epithelial cancer cells. Hum Gene Ther 9: 1049-1059. 
Mah, C., K. Qing, B. Khuntirat, S. Ponnazhagan, X.-S. Wang, D.M. Kube, M.C. Yoder, A. Srivastava (1998) Adeno-associated virus type 2 mediated gene transfer: role of epidermal growth factor receptor protein tyrosine kinase in transgene expression. J Virol 72: 98359843.

Manno, C.S., A.J. Chew, S. Hutchison, P.J. Larson, R.W. Herzog, V.R. Arruda, S.J. Tai, M.V. Ragni, A. Thompson, M. Ozelo, L.B. Couto, D.G.B. Leonard, F.A. Johnson, A. McClelland, C. Scallan, E. Skarsgard, A.W. Flake, M.A. Kay, K.A. High, B. Glader (2003) AAV-mediated factor IX gene transfer to skeletal muscle in patients with severe hemophilia B. Blood 101: 2963-2972.

Marchese, C., M. Sorice, C. De Stefano, L. Frati, M.R. Torrisi (1997) Modulation of keratinocyte growth factor receptor expression in human cultured keratinocytes. Cell Growth Differ 8: 989-997.

Miller, A.D (1996) Cell-surface receptors for retroviruses and implications for gene transfer. Proc Natl Acad Sci USA 93: 11407-11413.

Moss, R.B., D. Rodman, L.T. Spencer, M.L. Aitken, P.L. Zeitlin, D. Waltz, C. Milla, A.S. Brody, J.P. Clancy, B. Ramsey, N. Hamblett, A.E. Heald (2004) Repeated adeno-associated virus serotype 2 aerosol-mediated cystic fibrosis transmembrane regulator gene transfer to the lungs of patients with cystic fibrosis: a multicenter, double-blind, placebo-controlled trial Chest 125: 509-521.

Nakai, H., E. Montini, S. Fuess, T.A. Storm, M. Grompe, M.A. Kay (2003) AAV serotype 2 vectors preferentially integrate into active genes in mice. Nat Genet 34: 297-302.

Nakai, H., S.R. Yant, T.A. Storm, S. Fuess, L. Meuse, M.A. Kay (2001) Extrachromosomal recombinant adeno-associated virus vector genomes are primary responsible for stable liver transduction in vivo. Virology 75: 6969-6976.

Nicklin S.A., A.H. Baker (2002) Tropism-modified adenoviral and adeno-associated viral vectors for gene therapy. Curr Gene Ther 2: 273-293.

Nicklin, S.A., H. Büning, K.L. Dishart, M. de Alwis, A. Girod, U. Hacker, A.J. Tharsher, R.R. Ali, M. Hallek, A.H. Baker (2001) Efficient and selective AAV2-mediated gene transfer directed to human vascular endothelial cells. Mol Ther 4: 174-181.

Ohno, K., K. Sawai, Y. Iijima, B. Levin, D. Meruelo (1997) Cell-specific targeting of Sindbis virus vectors displaying IgG-binding domains of protein A. Nat Biotechnol 15: 763-767.

Opie, S.R., K.H. Warrington Jr., M. AgbandjeMcKenna, S. Zolotukhin, N. Muzyczka (2003) Identification of amino acid residues in the capsid proteins of adeno-associated virus type 2 that contribute to heparan sulfate proteoglycan binding. J Virol 77: 6995-7006.

Penel, N., J. Bonneterre (2003) Gene therapy of melanoma: review of published clinical trials. Rev Med Interne 24: 443-451.

Perabo, L., H. Büning, D.M. Kofler, M.U. Ried, A. Girod, C.M. Wendtner, J. Enssle, M. Hallek (2003) In vitro selection of viral vectors with modified tropism: the adeno-associated virus display. Mol Ther 8: 151-157.
Peus, D., L. Hamacher, M.R. Pittelkow (1997) EGF-receptor tyrosine kinase inhibition induces keratinocyte growth arrest and terminal differentation. J Invest Dermatol 109: 751756.

Pittelkow, M.R., P. Cook, G. Shipley, R. Derynck, R.I. Coffey (1993) Autonomous growth of human keratinocytes requires epidermal growth factor receptor occupancy. Cell Growth Differ 4: 513-521.

Ponnazhagan, S, G. Mahendra, S. Kumar, J.A. Thompson, M. Castillas Jr. (2002) Conjugatebased targeting of recombinant adeno-associated virus type 2 vectors by using avidin-linked ligands. J Virol 76: 12900-12907.

Ponnazhagan, S., P. Mukherjee, X.S. Wang, K. Qing, D.M. Kube, C. Mah, C. Kurpad, M.C. Yoder, E.F. Srour, A. Srivastava (1997) Adenoassociated virus type 2-mediated transduction in primary human bone marrow-derived CD34+ hematopoietic progenitor cells: donor variation and correlation of transgene expression with cellular differentiation. J Virol 71 : 8262-8267.

Ponnazhagan, S., X.S. Wang, M.J. Woody, F. Luo, L.Y. Kang, M.L. Nallari, N.C. Munshi, S.Z. Zhou, A. Srivastava (1996) Differential expression in human cells from the p6 promoter of human parvovirus B19 following plasmid transfection and recombinant adeno-associated virus 2 (AAV) infection: human megakaryocytic leukaemia cells are non-permissive for AAV infection. J Gen Virol 77: 1111-1122.

Qiao, C., J. Li, A. Skold, X. Zhang, X. Xiao (2002a) Feasibility of generating adeno-associated virus packaging cell lines containing inducible adenovirus helper genes. J Virol 76: 19041913.

Qiao, C., B. Wang, X. Zhu, J. Li, X. Xiao (2002b) A novel gene expression control system and its use in stable, high-titer 293 cell-based adenoassociated virus packaging cell lines. J Virol 76 : 13015-13027.

Qing, K., B. Khuntirat, C. Mah, D.M. Kube, X.-S. Wang, S. Ponnazhagan, S.Z. Zhou, V.J. Dwarki, M.C. Yoder, A. Srivastava (1998) Adenoassociated virus type 2-mediated gene transfer: correlation of tyrosine phosphorylation of the cellular single-stranded D sequence-binding protein with transgene expression in human cells in vitro and murine tissues in vivo. J Virol 72: 1593-1599.

Qing, K., C. Mah, J. Hansen, S. Zhou, V. Dwarki, A. Srivastava (1999) Human fibroblast growth factor receptor 1 is a co-receptor for infection by adeno-associated virus 2 . Nat Med 5: 7177 .

Rabinowitz, J.E., F. Rolling, C. Li, H. Conrath, W. Xiao, X. Xiao, R.J. Samulski (2002) Crosspackaging of a single adeno-associated virus (AAV) type 2 vector genome into multiple AAV serotypes enables transduction with broad specificity. J Virol 76: 791-801.

Rabinowitz, J.E., R.J. Samulski (2000) Building a better vector: the manipulation of AAV virions. Virology 278: 301-308.
Ried, M.U., A. Girod, K. Leike, H. Büning, M. Hallek (2002) Adeno-associated virus capsids displaying immunoglobulin-binding domains permit antibody-mediated vector retargeting to specific cell surface receptors. J Virol 76: 4559_ 4566.

Rizzo, W.B., Z. Lin, G. Carney (2001) Fatty aldehyde dehydrogenase: genomic structure, expression and mutation analysis in SjögrenLarsson syndrome. Chem Biol Interact 130 132: 297-307.

Russell, D.W., I.E. Alexander, A.D. Miller (1995) DNA synthesis and topoisomerase inhibitors increase transduction by adeno-associated virus vectors. Proc Natl Acad Sci USA 92: 5719 5723.

Samulski, R.J., X. Zhu, X. Xiao, J.D. Brook, D.E. Housman, N. Epstein, L.A. Hunter (1991) Targeted integration of adeno-associated virus (AAV) into human chromosome 19. EMBO J 10: $3941-3950$.

Sanlioglu, S., P.K. Benson, J. Yang, E.M. Atkinson, T. Reynolds, J.F. Engelhardt (2000) Endocytosis and nuclear trafficking of adeno-associated virus type 2 are controlled by rac1 and phosphatidylinositol-3 kinase activation. J Virol 74 9184-9196.

Sanlioglu, S., M.M. Monick, G. Luleci, G.W. Hunninghake, J.F. Engelhardt (2001) Rate limiting steps of AAV transduction and implications for human gene therapy. Curr Gene Ther 1: 137147.

Schnepp, B.C., K.R. Clark, D.L. Klemanski, C.A. Pacak, P.R. Johnson (2003) Genetic fate of recombinant adeno-associated virus vector genomes in muscle. J Virol 77: 3495-3504.

Seisenberger, G., M.U. Ried, T. Endress, H. Büning, M. Hallek, C. Bräuchle (2001) Real-time single-molecule imaging of the infection pathway of an adeno-associated virus. Science 294 . 1929-1932.

Shi, W., G.S. Arnold, J.S. Bartlett (2001) Insertional mutagenesis of the adeno-associated virus type 2 (AAV2) capsid gene and generation of AAV2 vectors targeted to alternative cell-surface receptors. Hum Gene Ther 12: $1697-$ 1711

Shi, W., J.S. Bartlett (2003) RGD inclusion in VP3 provides adeno-associated virus type 2 (AAV2)-based vectors with a heparan sulfateindependent cell entry mechanism. Mol Ther 7: 515-525

Smith, A.D., R.F. Collaco, J.P. Trempe (2003) Enhancement of recombinant adeno-associated virus type 2 -mediated transgene expression in a lung epithelial cell line by inhibition of the epidermal growth factor receptor. J Virol 77 . 6394-6404.

Snyder, R.O., C.H. Miao, G.A. Patijn, S.K. Spratt, O. Danos, D. Nagy, A.M. Gown, B. Winther, L. Meuse, L.K. Cohen, A.R. Thompson, M.A. Kay (1997) Persistent and therapeutic concentrations of human factor IX in mice after hepatic gene transfer of recombinant AAV vectors. Nat Genet 16: 270-276.

Stilwell, J.L., R.J. Samulski (2003) Adeno-associated virus vectors for therapeutic gene transfer. Biotechniques 34: 148-150. 
Summerford, C., J.S. Bartlett, R.J. Samulski (1999) AlphaVbeta5 integrin: a co-receptor for adenoassociated virus type 2 infection. Nat Med 5: $78-82$.

Summerford, C., R.J. Samulski (1998) Membraneassociated heparan sulfate proteoglycan is a receptor for adeno-associated virus type 2 virions. J Virol 72: 1438-1445.

Sun, J.Y., V. Anand-Jawa, S. Chatterjee, K.K Wong (2003) Immune responses to adeno-associated virus and its recombinant vectors. Gene Ther 10: 964-976.

Sun, L., J. Li, X. Xiao (2000) Overcoming adenoassociated virus vector size limitation through viral DNA heterodimerization. Nat Med 6 . 599-602.

Surosky, R.T., M. Urabe, S.G. Godwin, S.A. McQuiston, G.J. Kurtzman, K. Ozawa, G. Natsoulis (1997) Adeno-associated virus Rep proteins target DNA sequences to a unique locus in the human genome. J Virol 71: 79517959.

Thomas, C.E., A. Ehrhardt, M.A. Kay (2003) Progress and problems with the use of viral vectors for gene therapy. Nat Rev Genet 4: 346-358.
Walter, W., U. Stein (1996) Cell type specific and inducible promotors for vectors in gene therapy as an approach for cell targeting. J Mol Med 74: 379-392.

Watt, F.M. (2000) Epidermal stem cells as targets for gene transfer. Hum Gene Ther 11: 22612266.

White, St.J., St.A. Nicklin, H. Büning, J. Brosnan, K. Leike, E.D. Papadakis, M. Hallek, A.H. Baker (2004). Targeted gene delivery to vascular tissue in vivo by tropism-modified adenoassociated virus vectors. Circulation 109: 513519.

Wu, P., W. Xiao, T. Conlon, J. Hughes, M. Agbandje-McKenna, T. Ferkol, T. Flotte, N. Muzyczka (2000) Mutational analysis of the adeno-associated virus type 2 (AAV2) capsid gene and construction of AAV2 vectors with altered tropism. J Virol 74: 8635-8647.

Xiao, X., J. Li, R.J. Samulski (1996) Efficient longterm gene transfer into muscle tissue of immunocompetent mice by adeno-associated virus vector. J Virol 70: 8098-8108.

Xiao, X., J. Li, R.J. Samulski (1998) Production of high-titer recombinant adeno-associated virus vectors in the absence of helper adenovirus. $\mathbf{J}$ Virol 72: 2224-2232.
Xie, Q., W. Bu, S. Bhatia, J. Hare, T. Somasundaram, A. Azzi, M.S. Chapman (2002) The atomic structure of adeno-associated virus (AAV-2), a vector for human gene therapy. Proc Natl Acad Sci USA 99: 10405-10410.

Yakobson, B., T.A. Hrynko, M.J. Peak, E. Winocour (1989) Replication of adeno-associated virus in cells irradiated with UV light at $254 \mathrm{~nm}$. J Virol 63: 1023-1030.

Yalkinoglu, A.O., R. Heilbronn, A. Burkle, J.R. Schlehofer, H. zur Hausen (1988) DNA amplification of adeno-associated virus as a response to cellular genotoxic stress. Cancer Res 48 . 3123-3129.

Yalkinoglu, A.O., H. Zentgraf, U. Hubscher (1991) Origin of adeno-associated virus DNA replication is a target of carcinogen-inducible DNA amplification. J Virol 65:3175-3184.

Yang, Q., M. Mamounas, G. Yu, S. Kennedy, B. Leaker, J. Merson, F. Wong-Staal, M. Yu, J.R. Barber (1998) Development of novel cell surface CD34-targeted recombinant adenoassociated virus vectors for gene therapy. Hum Gene Ther 9: 1929-1937. 